\title{
Mentoring Activities in a Summer School
}

\author{
http://dx.doi.org/10.3991/ijep.v3iS1.2407 \\ J.C. Marques, M.T. Restivo and M.F. Chouzal \\ Universidade do Porto, Porto, Portugal
}

\begin{abstract}
Universidade Júnior is a very large educational program for the promotion of knowledge among preuniversity children and teenagers launched in 2005 by U.Porto. This extremely popular initiative is currently attracting around 5000 students per year for a variety of learning activities and small research projects offered by the 14 Faculties of U.Porto during July and September. Besides providing a foretaste of university life and vocational orientation, they also give the youngsters a strong incentive to continue their studies into higher education and a knowledge-based career. A key element to the success of this process is the mentoring activity that is developed at two levels: between faculty and the junior tutors and between these and the young students.
\end{abstract}

Index Terms-Competencies development, educational programs at STEM level, multidisciplinary activities, youth mentoring.

\section{INTRODUCTION}

This paper describes teaching, learning and mentoring activities developed in the context of Junior University (Universidade Júnior - U.Jr.) [1], an initiative of U.Porto aimed at youngsters in the 11 to 17 age group.

U.Jr. is a very successful summer school program launched by U.Porto in 2005 whose main goal is the promotion of knowledge in the fields of science, technology, art, humanities and sport, with the objective of attracting secondary school students to higher education in general, to U.Porto in particular and also, more specifically, to science and engineering, an area with a deficit of students enrolling in this type of university degree [2].

According to the EU 2020 strategy, by that year $40 \%$ of Europeans between the ages of 30 to 34 are expected to have higher education degrees. The achievement of this goal demands that more young people should enter higher education. And a great help will obviously come from giving to youngsters the chance to see as closely as possible what university is like.

U.Porto's Junior University is a founding member of EUCU.NET, the European Children's Universities Network [3], an independent non-profit organization whose aim is to support networking, quality development and to make the outcomes more traceable and comparable, as demanded by the diversity of models currently adopted in more than 200 locations all over Europe.

U.Jr. is an example of a project mentoring approach at two levels. The academic staff member responsible for each action acts as a mentor of the junior tutors, who are final year students, recent graduates or in some cases junior researchers. On the other hand the tutors are the mentors of the youngsters who attend the various actions that integrate the U.Jr. program in the 14 Faculties of U.Porto.

Mentoring in the context of Engineering Education is being explored in various formats, namely in the so called "Project- Mentoring" [4] at Leuphana University of Lüneburg, a competence-oriented teaching and learning approach based on the constructivist learning theories by supporting collaborative and active learning. The mentoring relationship between students as mentors and secondary school pupils as mentees is combined with actionoriented engineering projects developed in the course of one semester.

The time scale is the major difference in the case of U.Jr. given its summer school character, but the perceived benefits for both tutors and young students are of similar nature, namely the development of leadership and other soft skills for the former and an eye-opener and a strong incentive for the latter to pursue higher education.

\section{JUNIOR UNIVERSITY - THE CONCEPT}

U.Jr. comprises two parts: the General Program and the U.Jr. Science Schools [1].

The General Program takes place during 4 weeks in July offering several formats according to the age of the pupils. There is a choice between "Try It in the Summer" (for 11-12 years old), "Summer Workshops" and "Thematic Workshops" (both for 13-14 years old), "Summer Projects" (for 15-17 years old) and the "Language Schools" (for 11-17 years old).

They run Monday to Friday, 09:00 to 18:00, with one week duration (two in the case of Language Schools). The participants have their meals at the canteens like regular students which also contribute to make them feel integrated in university life. Each group has at most 14 members with two junior tutors under the coordination of one member of the academic staff.

A sample of the "Try It in the Summer" and of the "Summer Workshops" programs on offer for July 2012 is shown in Tables I and II. One different activity is explored daily, in various faculties along the week.

TABLE I.

“Try It In The SuMMER” SAMPLE WeEK PROgRAM (1 OF 5)

\begin{tabular}{|l|l|c|}
\hline \multicolumn{1}{|c|}{ Day } & \multicolumn{1}{c|}{ Theme } & Faculty \\
\hline Mon. & An artist of the Paleolythic & Fine Arts \\
\hline Tue. & The missing papyrus & Humanities \\
\hline Wed. & My footprint is bigger than yours & Sciences \\
\hline Thu. & Healthy teeth & Dental Medicine \\
\hline Fri. & Swimming, water polo and diving & Sport \\
\hline
\end{tabular}


TABLE II.

“SUMMER WORKSHOPS” SAMPLE WEEK PROGRAM (1 OF 6)

\begin{tabular}{|l|l|c|}
\hline Day & \multicolumn{1}{|c|}{ Theme } & Faculty \\
\hline Mon. & Treasure hunting & Economics \\
\hline Tue. & Exploring materials & Engineering \\
\hline Wed. & Volleyball is great fun & Sport \\
\hline Thu. & Mathematical mysteries in Egypt & Sciences \\
\hline Fri. & Portugal 2050 & Humanities \\
\hline
\end{tabular}

In 2012 a new format, entitled "Thematic Workshops", has been introduced for the first time. Four specific topics have been addressed: Arts; the City of Porto; Matter and Life; Life and Health.

In the "Summer Projects" each pupil is allocated a personal project for development during the week. They are expected to take home the final outcome. A total of 67 Summer Project topics were available in the 2012 U.Jr. edition, six of them proposed by the Faculty of Engineering including: Bioengineering at the service of man food, environment, energy and health; Make your first short film; The small great world of nanotechnology; Discover mechatronics; Modelling 3D objects; Let's try Chemical Engineering; The automobile under the magnifying glass.

In 2012 there were 8 Language Schools: German, Spanish, French, English, Japanese, Greek, Latin and Russian.

The second part of U.Jr., the Science Schools, is scheduled for the beginning of September and provides a choice of four one-week advanced workshops for introducing to research selected top 10th and 11th grade students: Life and Health Sciences; Physics; Chemistry and Biochemistry; Mathematics.

A nominal fee is charged to cover lunches, afternoon snacks, field trips (Fig.1) and the various activities.

The program also provides accommodation for an additional fee to those who come from outside Porto. They are supervised by other tutors who take care of evening meals and leisure activities, such as a late afternoon swim in the sea, a football match on the beach and visits to historical and cultural spots in Porto.

The age distribution in the 2011 U.Jr. edition is shown in Fig. 2 (with 43\% male participants), while the main thematic areas are depicted in Fig.3.

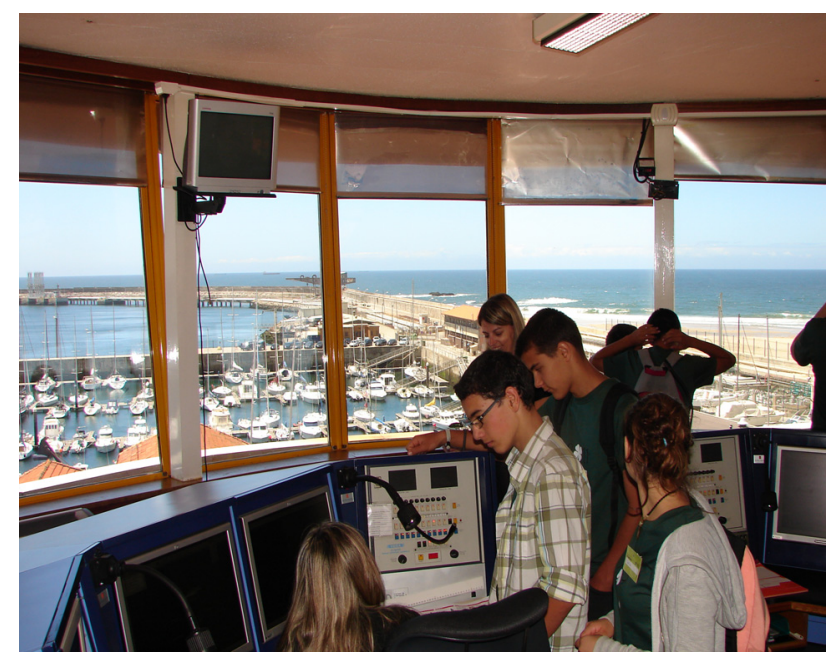

Figure 1. Field trip to Leixões Harbour control tower

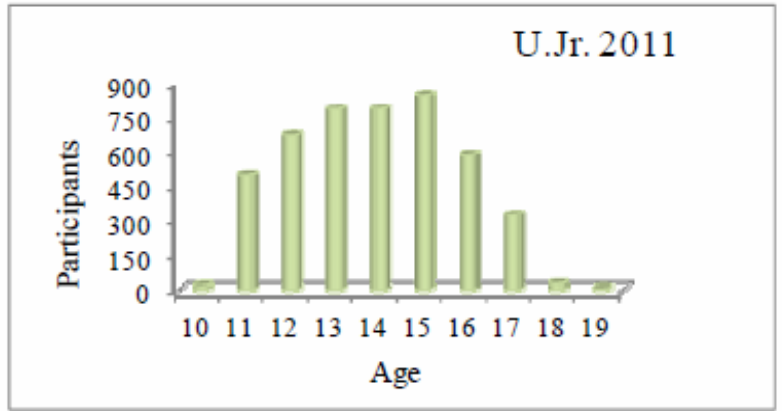

Figure 2. Age distribution in the 2011 edition [5]

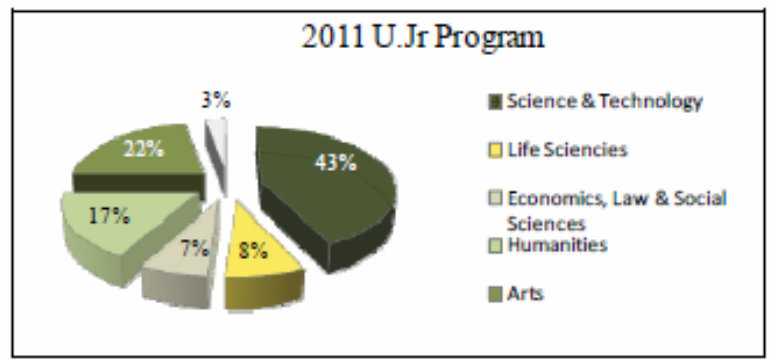

Figure 3. Thematic areas in U.Jr. 2011 [5]

From the U.Jr. inception in 2005 the number of participants has quickly risen to around five thousand who come from all over the country and even from abroad (United States, Brazil, France, England, Spain, Ireland, Holland, Macau, Angola, Mozambique, St. Tomé and Príncipe).

The geographical distribution patterns of recruitment areas for both U.Jr. participants in 2006-2010 and U.Porto students in 2007-2011 are compared in Fig. 4. They are not significantly different (with a Pearson index of 0.95) with U.Jr. exhibiting a slightly wider geographical dispersion [5].

U.Jr. has had a positive impact in the number of applications to U.Porto in general and most likely also in those to the Faculty of Engineering in particular [5].

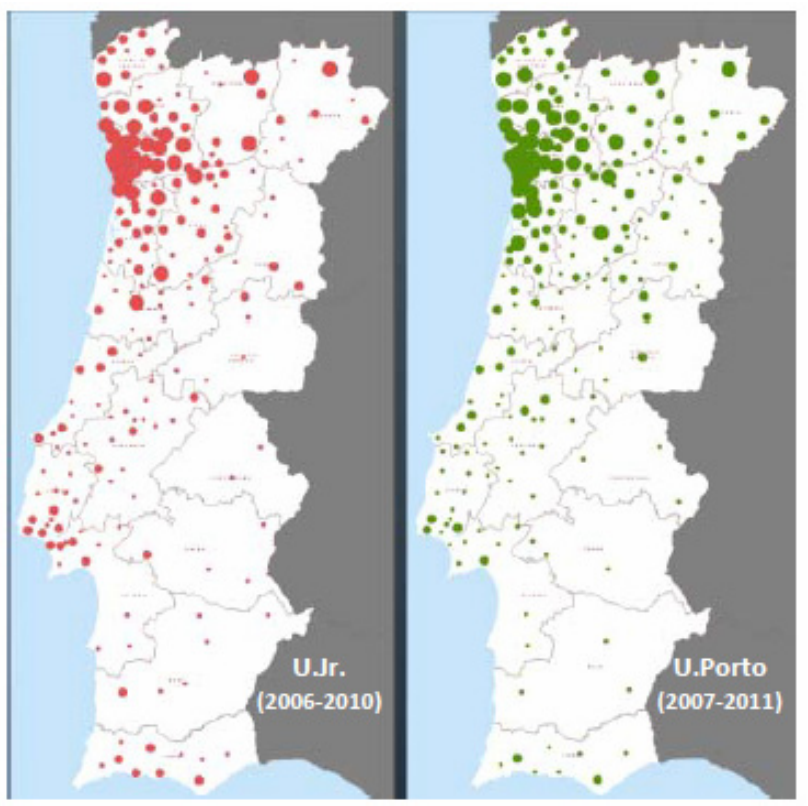

Figure 4. Geographical origin of U.Jr. participants and U.Porto students [5] 


\section{MENTORING}

U.Jr. requires careful planning, not only in the design and fine tuning of the various types of actions offered to the participants, but also in the selection and training of the junior tutors, the students who are in charge of controlling, guiding, motivating and interacting with the secondary school pupils.

Tutor selection takes into account their academic record as well as their maturity and interpersonal skills. Previous experience in group activities such as boy scouting, Sunday school or team sports usually proves to be an asset.

The training of tutors starts by covering basic aspects related to the logistics, schedule, responsibility and rules of behaviour for tutors and pupils in U.Jr..

Additional specific training is conveyed by lecturers from the Faculty of Education Sciences and Psychology, whereby some guidelines concerning the psychology of interaction with youngsters, group dynamics and conflict solving are provided.

This is then complemented by scientific and technical mentoring of the junior tutor team assigned to each activity by the senior academic staff members who are responsible for conceiving, proposing and organizing it.

Then each pair of tutors is finally faced with the real challenge, to be in charge of a 14-pupil group during a full week, to interact creatively with them, to make good use of their energy, to stimulate their curiosity, to guide them in the path of discovery.

A wide range of soft skills is called into play, specifically leadership, communication, empathy, conflict management and emotional intelligence in what concerns the tutors, while the pupils have the chance to train teamwork, sociability and responsibility in the context of collaborative and active learning.

\section{FEEDBACK From U.JR. ACtIVITIES AT FEUP}

The tutors of the summer workshop activity entitled "Discovering Mechanical Engineering" organized in this Department in the period 2006-2008, have gathered over 800 end-of-activity questionnaires.

In general students express very positive opinions about 5 particular items: the tutors, the social interaction, the hands-on experiments, the new friends and the contact with University reality, Fig. 5.

In addition, many identify the assistance given by U.Jr. activities in defining future options or in strengthening their motivation to pursue higher education. This type of feedback is consistent with the trend that emerges from opinions collected from U.Jr. participants elsewhere in U.Porto.

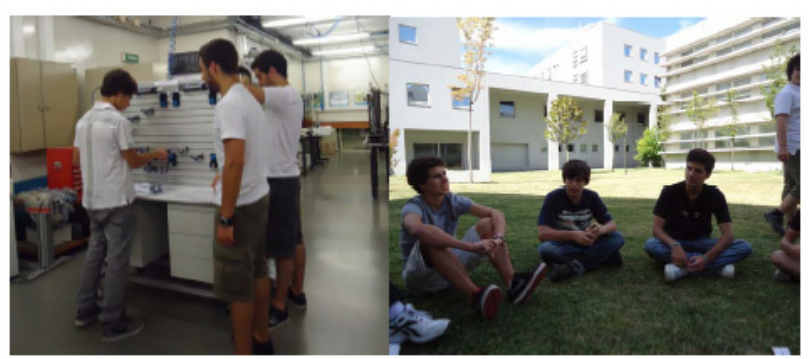

Figure 5. Hands-on activity and social interaction
From the tutor side the main references point to the valuable experience gained in group leadership, time and task management, capacity for improvising and reacting in response to unexpected situations and, above all, the know-how for transmitting knowledge in an appealing manner through team work and the ability to engage and sustain the youngsters attention. The testimonies are now registered of five tutors who have been involved in U.Jr. activities at FEUP between 2005 and 2012.

Júlio Pinto (2005-2009) - "The greatest challenge was to keep the students highly motivated during the whole week. This was greatly helped by the progress gradually being achieved in the work. The youngsters wanted to see the Faculty from the inside, to get a feel for what was to come. Later I had the chance to meet some of those kids and they all expressed fond memories of those days. Many of them chose to study engineering at FEUP.”

Ricardo Magalhães (2006-2008) - "My activity was called "A small great can". During one week we made several experiments using soft drink cans, measuring their strain and the mechanical and physical characteristics of their material. I still recall the amazement of the teenagers as they realized the vast amount of knowledge and knowhow encapsulated in such a trivial object. There is no better way to explain why engineering exists than to offer to youngsters the chance to get in touch with all the whys and hows of daily life items. Another major aspect of this experience has been to help the students formulate and solve their questions about choice of degree and faculty.”

Danilo Fernandes (2006-2009) - "In my opinion U.Jr. has all the features for being a highly praised project at national and international level. U.Jr. is the proof that learning is fun. To my knowledge no other program offers such enriching and unforgettable experiences to youngsters in the 11 to 17 age group. I think that the success of this program is inherent in its conception. The activity proponents start by thinking up imaginative topics for successfully engaging young people. Adequate technoscientific support material is prepared. Then tutors are selected on the basis of their soft skills and adequately trained. All this paves the way for providing the students with an intense and pleasurable week of team work, learning new things and making new friends, which will be remembered for many years. Tutors increase their interpersonal and leadership skills, develop time and conflict management expertise, become more resourceful and ready for solving any emerging issue. They also become proficient at combining group animation with knowledge transmission in an appealing fashion.”

Sara Fernandes (2001-2012) - “The summer project "Discover Mechatronics" has required the preparation of clear and informative materials for introducing a complex subject without compromising accuracy and objectivity. The sharing of knowledge in an efficient while also simple and amusing way has been a real challenge that greatly developed my communication and leadership skills, two most valuable assets for my future professional life. Keeping the group engaged during the whole week, with high motivation and commitment, has been a very successful achievement.”

Ruben Almeida (2011-2012) - "It is important for the tutor to be also seen as a friend in what has been a very rewarding experience. When you enjoy what you are doing nothing is difficult and everything becomes easy.” 


\section{ACTIVITY EXAMPLES}

This section starts by describing two activities promoted by the Mechanical Engineering Department. The first one ("A Small Big Can”) involved youngsters in the 11-12 age group during a week, while the second (entitled "Discovering Mechanical Engineering") was a one-day event aimed at 13-14 years old. This is followed by a brief reference to four additional one-day activities organized by other Faculties of U.Porto.

\section{A. A Small Big Can}

The main goal of this one-week project is to explore various experimental activities focused on a very familiar object, the well-known beverage can, in order to unveil some of its less apparent features. It is a strongly multidisciplinary project including several mechanical engineering areas: measurement instrumentation and procedures, materials and processes, experimental optics and management.

Some of the topics related with measurement instrumentation within this activity are, e.g., the can dimensional measurement, the evaluation of the pressure inside the closed can, the can behaviour during opening, how to instrument the beverage can for determining its strains, Fig. 7. The pupils are facing for the first time strain gauge sensors and how to use them for measuring strain. They are also stimulated to try to prove experimentally the strain gauge concept. Other concepts related with mechanical properties of materials as Young's modulus and Poisson's ratio are also conveyed.

The beverage cans available in the market look similar in shape and size, although they are produced with differ-

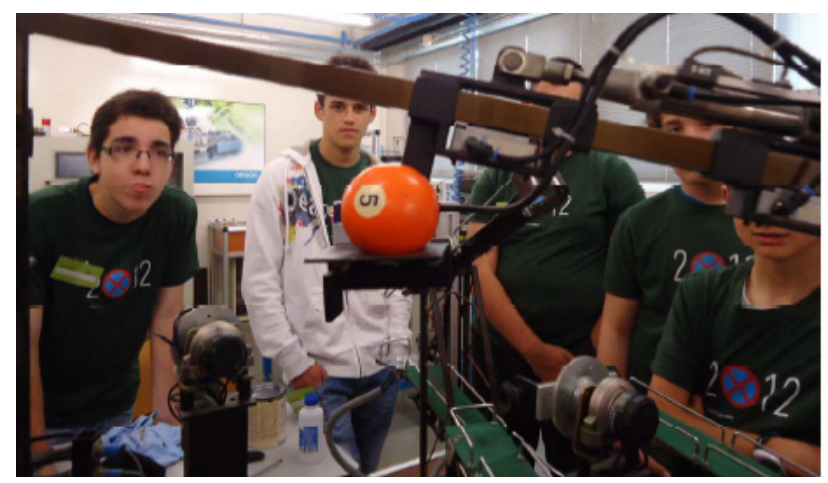

Figure 6. Discovering Mechatronics

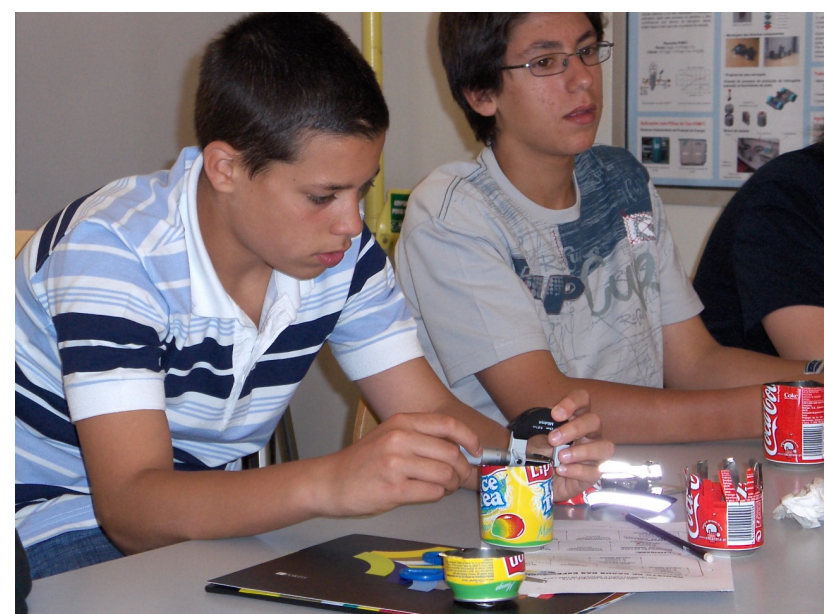

Figure 7. Beverage can dimensional measurement ent materials. A set of tests are performed by the pupils in order to identify those materials and to explore some of their characteristics.

Data is also extracted using 3D optical image analysis and the pupils have the chance to apply this technologically advanced method, [8-9], Fig. 8.

Looking at the beverage can as a market product a game in the management area is used for a new activity. The goal is to understand how to be efficient and competitive in a commercial distribution process, Fig. 9.

After exploring in the morning the management activity the afternoon was devoted to a visit to UNICER, a brewery and a soft drinks company near Porto, Fig.10. The pupils, together with one of the project teachers and one tutor, were able to observe many details and to ask questions about topics dealt with during this project, mainly related with the management game.

In the final activity the pupils were asked to contribute creatively to the "Can Parade", a can painting contest which was later evaluated by a colleague from the Fine Arts Faculty.

This Project led to the establishment of a link that lasted a couple of months between the youngsters and the tutor team via a web page of multidisciplinary activities at FEUP.

Due to the strong multidisciplinary character of this Project the tutor selection process was very decisive as well as their mentoring in the course of the various activities by the teachers involved.

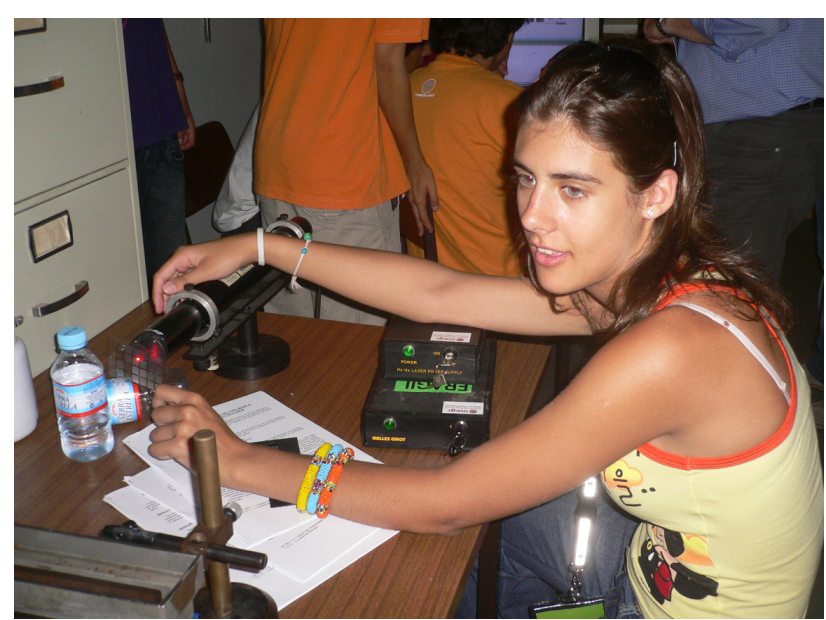

Figure 8. Working with light

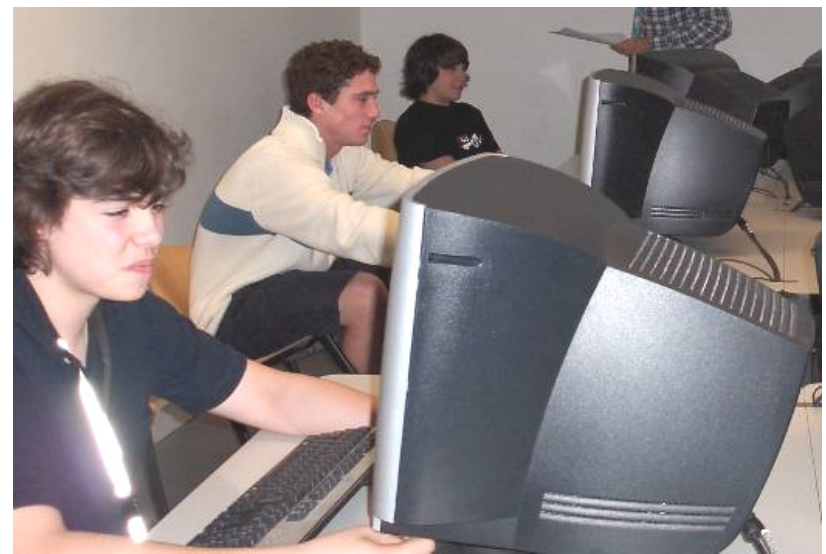

Figure 9. Management game session 


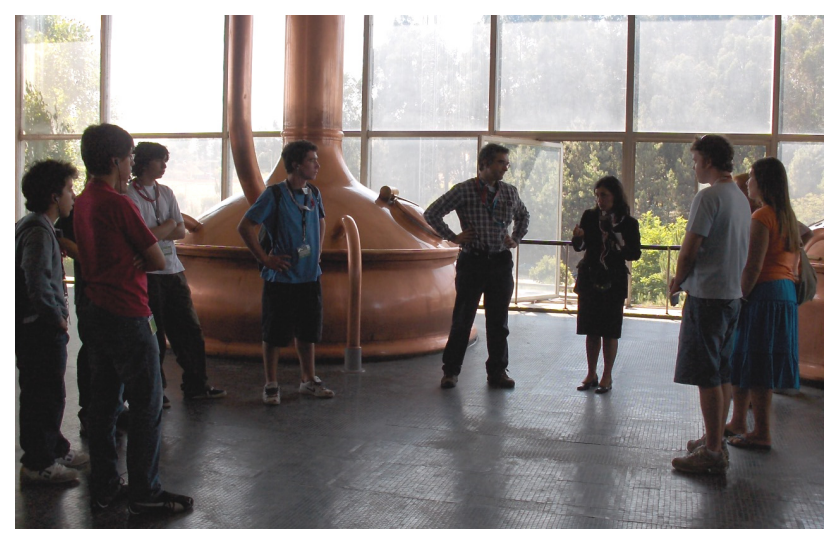

Figure 10. Visit to a brewery and a soft drinks company

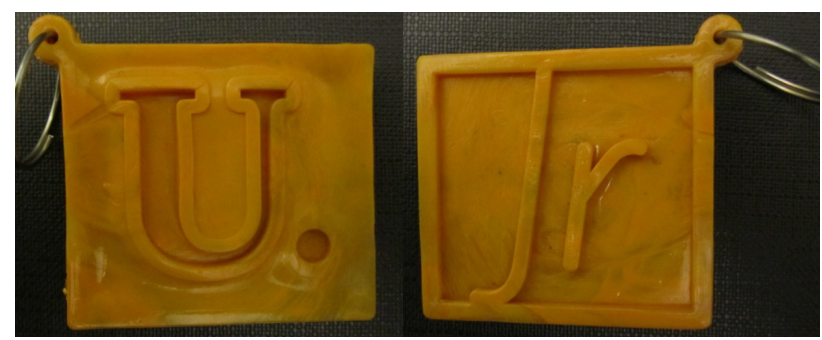

Figure 11. Manufactured keychain fob

\section{B. Discovering Mechanical Engineering}

The program for this one day activity (within a week comprising four additional activities) was prepared with the main goal of explaining that mechanical engineering has a very wide field of applications dealing with many things other than just cars, a common perception shared by many youngsters.

During this very busy day the pupils start by getting in touch with laboratory experiments that are also remotely accessible. Later they have the chance to control them via the web, which gives them a feel for online engineering.

Another activity is dedicated to the identification of a large set of various common materials by exploring them at the lab. They are also introduced to some manufacturing processes such as casting, stamping and plastic injection, besides collaborating in the manufacturing of a fob for a keychain, using a small prototyping press, Fig.11.

Experiments with light sources are the next activity. The idea is to demonstrate how to use light for measuring stress, strain, length and geometry, by using light coherence and polarization principles.

The youngsters also visited other labs and workshops in the Mechanical Engineering Department.

At the end of the day they understand that mechanical engineering is present in a wide range of fields, even in areas like wind power energy, solar energy, remote control, which are usually perceived as akin to electrical engineering.

It is worth mentioning that this one-day activity at the Faculty of Engineering has been complemented by another four that took place in other Faculties and which are now briefly summarized.

\section{More Summer Workshops}

"Cyanotypes and photograms" (Faculty of Arts): the activity offers an introduction to photographic printing techniques involving hands-on action in and outdoors and fostering creativity and curiosity about ways to make images with light.

"Discovering Gaia Coast" (Faculty of Sciences): This activity aims to alert participants to the importance of the coast, integrating natural and anthropic aspects since these cannot be dissociated from rivers, people and the climate. Particular emphasis is given to the Douro River and its estuary, to dunes and their vegetation, to coastal dynamics and the preservation of its vegetal and animal life. Biology is the main focus of this activity.

"Treasure Hunt” (Faculty of Economics): Based in the "Treasure Hunt" game philosophy, the activity uses puzzles, challenges and everyday concepts from Economics and Management. It reinforces the teamwork effort for enigmas' discovery and resolution. The main objective of this activity is to integrate the information gathered throughout the game, making up a summary of experiences and trying to reflect about the career opportunities in this area. A search of treasure will be the last step, and the same shall be composed of various materials, Faculty, some informative and others entertainment.

"Swimming and jumping into the water" (Faculty of Sports): This is a multidisciplinary sport activity, which aims to highlight that the behaviour of the human being in aquatic environment is inherent and specific to each type of water sport, involving hydrostatic and hydrodynamic principles. Exercises including different techniques are used for demonstration and training purposes.

\section{ACKNOWLEDGMENTS}

The "father" of U.Jr., Professor José Ferreira Gomes deserves a special reference for his vision in launching this program. Paulo Gusmão, Filomena Mesquita and Vítor Silva are the U.Jr. master team who controls all this complex activity and must also be mentioned here. And last but not the least the authors wish to thank Júlio, Ricardo, Danilo, Ruben and Sara for their testimonies, which brought back memories of their enthusiasm and dedicated collaboration.

We also wish to thank to our colleagues who contributed to the "A small big can” project, Teresa Duarte, Mário Vaz and José Barros Basto.

\section{REFERENCES}

[1] www.universidadejunior.up.pt.

[2] J. Ferreira Gomes, "Universidade Júnior, a project to motivate school pupils”. Proc. ICECE 2007, International Conference on Engineering and Computer Education, 2007, pp.199-203, C.R. Brito et al. (eds.), Santos, Brazil.

[3] http://eucu.net/.

[4] B.-M. Block and A. Georgiadis, "Project-Mentoring in Engineering Education - a competence-oriented teaching and learning approach”, EDUCON 2012, Marrakesh.

[5] V. Silva, P. Gusmão and F. Mesquita, "From the Junior University to the "Real" University - The effect on student recruitment at the University of Porto of a children and teens' University," SiS Catalyst \& EUCU.NET Joint Conference, University of Ankara, November 2011R.

[6] W.F. Hosford and J.L. Duncan, “The Aluminum Beverage Can”, Scientific American, vol. 271, no. 3, pp. 34-39, September 1994. http://dx.doi.org/10.1038/scientificamerican0994-48

[7] J.C. Marques, M.T. Restivo, P. Portela and R. Teixeira, "Cooperative teaching exploring a multidisciplinary engineering problem”, Proceedings of ASEE Annual Conference \& Exposition, Montreal, Canada, June 2002. 
[8] F. Chen, G. Brown and M. Song, "Overview of three-dimensional shape measurement using optical methods”, Optical Engineering, 39, pp. 10-22, January 2000.

[9] K. Creath, “Temporal phase measurement methods," in "Digital Fringe Pattern Measurement Techniques, D W Robinson and G T Reid, Eds. Bristol: Institute of Physics Publishing, 1993, pp. 94140.

\section{AUTHORS}

J. C. Marques is with Universidade do Porto, Faculdade de Engenharia, Porto, Portugal (e-mail: jmarques@fe.up.pt).

M. T. Restivo is with Universidade do Porto, Faculdade de Engenharia and with UISPA Research Unit at IDMEC-Pólo FEUP, Porto, Portugal (e-mail: trestivo@fe.up.pt).

M. F. Chouzal, is with Universidade do Porto, Faculdade de Engenharia and with UISPA Research Unit at IDMEC-Pólo FEUP, Porto, Portugal (e-mail: fchouzal@fe.up.pt).

This article is an extended and modified version of a paper presented at the IGIP2012 conference, held 26 - 28 September 2012, in Villach, Austria. Received 30 November 2012. . Published as resubmitted by the authors on 28 January 2013.. 